\title{
Development And Research Of The Press Operating Mechanism, Made In The Form Of The Wedge-Joint Mechanism With A Curving Wedge For Separation Operations
}

Sergii G. Karnaukh

Donbass State Engineering Academy

Nataly V. Chosta

Donbass State Engineering Academy

Oleg E. Markov ( $\boldsymbol{D}$ oleg.markov.omd@gmail.com )

Donbass State Engineering Academy https://orcid.org/0000-0001-9377-9866

Volodymyr V. Kukhar

Donbass State Engineering Academy

\section{Research Article}

Keywords: wedge-joint mechanism, curving wedge, link, slide, force, elastic deformation, shift cut, billet

Posted Date: April 8th, 2021

DOI: https://doi.org/10.21203/rs.3.rs-398559/v1

License: (c) (i) This work is licensed under a Creative Commons Attribution 4.0 International License. Read Full License

Version of Record: A version of this preprint was published at The International Journal of Advanced Manufacturing Technology on July 19th, 2021. See the published version at https://doi.org/10.1007/s00170-021-07718-8. 


\title{
RESEARCH ARTICLE
}

\section{DEVELOPMENT AND RESEARCH OF THE PRESS OPERATING MECH- ANISM, MADE IN THE FORM OF THE WEDGE-JOINT MECHANISM WITH A CURVING WEDGE FOR SEPARATION OPERATIONS}

\author{
Sergii G. Karnaukh ${ }^{1}$ PhD, Nataly V. Chosta ${ }^{2}$ PhD, Oleg E. Markov ${ }^{3}$ prof., Volodymyr V. Kukhar ${ }^{4}$ \\ prof. \\ ${ }^{1}$ Basics of Designing a Machine, Donbass State Engineering Academy, Akademichna Str.,
}

72, Kramatorsk, Ukraine, 84313, ORCID: http://orcid.org/0000-0003-2878-4065, k_sergii@i.ua

${ }^{2}$ Basics of Designing a Machine, Donbass State Engineering Academy, Akademichna Str., 72, Kramatorsk, Ukraine, 84313, ORCID: https://orcid.org/0000-0001-5275-6414, nataly-

\section{chosta@i.ua}

${ }^{3}$ Computerized Design and Modeling of Processes and Machines, Donbass State Engineering Academy, Akademichna Str., 72, Kramatorsk, Ukraine, 84313, ORCID: http://orcid.org/00000001-9377-9866, oleg.markov.omd@gmail.com

${ }^{4}$ Metal Forming Department, Pryazovskyi State Technical University, Universytetska str., 7, Mariupol, Ukraine, 87555, ORCID: http://orcid.org/0000-0002-4863-7233, kvv.mariupol@gmail.com

*Corresponding author. E-mail: oleg.markov.omd@gmail.com

\section{Abstract}

The applicability of a wedge-joint mechanism with a curving wedge in presses for the implementation of metal forming separation processes was substantiated. The paper states the fact, that the wedge-joint mechanism graph of the deformation force change is the closest to the technological typical graph of the force change during separation. At the same time, the wedge-joint mechanism with a curving wedge has a lower height of the parts in comparison with the traditional crank mechanisms, which provides less elastic deformation and press dynamics. The use of the additional wedge mechanism in a press with the wedge-joint mechanism with a curving wedge to ensure the approximation motion is proved. This makes it possible to reduce the energy consumption for elastic deformation and further reduce the dynamic force. The mathematical models of the wedge-joint mechanism with a curving wedge, presented in the form of a two-slide link mechanism, were developed, allowing to perform its structural, kinematic and dynamic analysis. Based on the analysis of the proposed mathematical models, dependencies were identified and a procedure for calculating the geometric, kinematic and power parameters of wedge-joint mechanisms with a curving wedge for separation processes was developed. Comparison of the kinematic and dynamic analyzes results carried out by analytical and graphicanalytical methods confirms the reliability of estimates, since their discrepancy is not more than $2.5 \%$. Experimental studies have confirmed the adequacy of mathematical 
models. The error between the calculated and measured values of the forces on the slide does not exceed $10 \%$.

Key words: wedge-joint mechanism, curving wedge, link, slide, force, elastic deformation, shift cut, billet

\section{Introduction.}

Rational use of metal, saving energy resources, reducing labor intensity and improving product quality are important tasks that should be solved at all technological stages of metalworking production, including the materials forming and a component of these processes - the separation of rolled steel into cut-to-length sections. Currently, in the field of separation operations, traditional technologies are used, implemented on well-known serial equipment - presses and shears, so progress is possible provided that new techniques are applied in technologies using non-standard mechanisms in machines [1-6].

\section{Analysis of literature data and problem statement.}

Separation operations are among the most common in the metal forming processes. They are carried out both on specialized press-forging equipment: shears, cold breakers, etc., and on all purpose one: hydraulic and mechanical presses, hammers, press hammers, in which, as actuators, hydraulic cylinders, crank, toggle, screw mechanisms are used. They are, as a rule, multi-link and have a relatively low rigidity $[2,3]$.

A number of scientists have made a significant contribution to the creation and subsequent development of scientific foundations for the development of equipment and technologies for the implementation of waste-free methods for separating bar sections [4-8]. Mechanical presses abroad are produced by such countries as: USA, Germany, Japan, England, etc., companies: National, Eumuco, Haserclever, Erie, etc. [9-11].

Separation operations differ from other forming operations by the fact that they require maximum separation force at the beginning of the working motion. At the same time, in the most popular crank presses and shears, the maximum force on the slide, on the contrary, is provided at the end of the working motion. Therefore, it can be stated that traditional crank mechanisms, which are the main actuators in this equipment, do not provide the required nature of the power load during separation. Because of this, it is necessary to choose crank presses with a nominal force much higher than the technological separation force. As a result, the power of the pressing equipment is not fully utilized. The press operating factor $k_{p}$ was taken as an indicator of the presses use by force. Literature sources provide information on the value of $k_{p}$. When using pressing equipment with a force of less than $2 \mathrm{MN}$, the press operating factor is equal to $k_{p}=0.6 \ldots 0.8$, with a force of less than $4 \mathrm{MN}-k_{p}<(0.4 \ldots 0.6)$, with a force of more than $4 \mathrm{MN}-k_{p}<0.4$ [4].

The further development of press-forging equipment for the implementation of separation operations is inextricably linked with the search and conduct of a wide range of complex scientific research of executive mechanisms, which, according to the graph of deformation force change, would be as close as possible to the typical 
graph of separation processes forces characteristic. Such an operating mechanism is the proposed wedge-joint mechanism with a curving wedge.

\section{The goal of the study.}

The goal of the work is to substantiate the use of a wedge-joint mechanism with a curving wedge in relation to separation operations and, on the basis of structural, kinematic and dynamic analysis, to develop a methodology for calculating the geometric, kinematic and force parameters of presses with such an operating mechanism.

The wedge-joint mechanism of the press (Fig. 1) consists of a curving wedge 1, a link 2 and a slide 3 . The wedge 1 has two working surfaces, one of which is flat and is in resting contact upon a thrust piece - the press top-end transverse member. The second working surface of the wedge is curving cylindrical with the radius $\mathrm{R}$ and mates with the protruding cylindrical surface of the link 2 . The link 2 has a second protruding cylindrical working surface, with a radius $r$ and mates with the curving cylindrical surface of the slide 3. The wedge-joint mechanism works as follows. Under the action of the drive force $\mathrm{F}_{\mathrm{h}}$, the curving wedge 1 moves horizontally by the amount of stroke $h_{h}$, affects the link 2, which, turning around, moves the slide 3 . The slide 3 performs a vertical working stroke $\mathrm{h}_{\mathrm{h}}$, affecting the billet by the force $F_{V}$, equal in magnitude to the force useful resistance of the billet, and, reaching the lowest point, returns to its original position.

It is advisable to carry out theoretical studies of the wedge-joint mechanism with a curving wedge by analytical, graphic-analytical methods used in the theory of mechanisms and machines, as well as in calculating the parameters of press-forging equipment, by methods of mathematical modeling $[12,13]$.

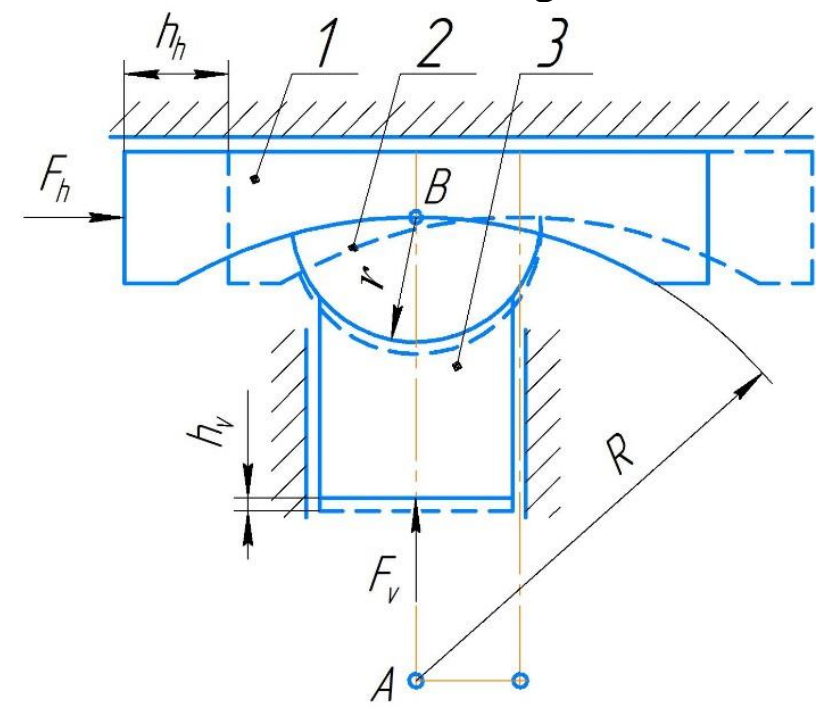

Figure: 1. Scheme of a wedge-joint mechanism with a curving wedge

The mode of the links motion in the wedge-joint mechanism is similar to the motion mode of the two-slide link mechanism parts, and, therefore, the structural diagrams of these mechanisms are identical (Fig. 2) [5]. 


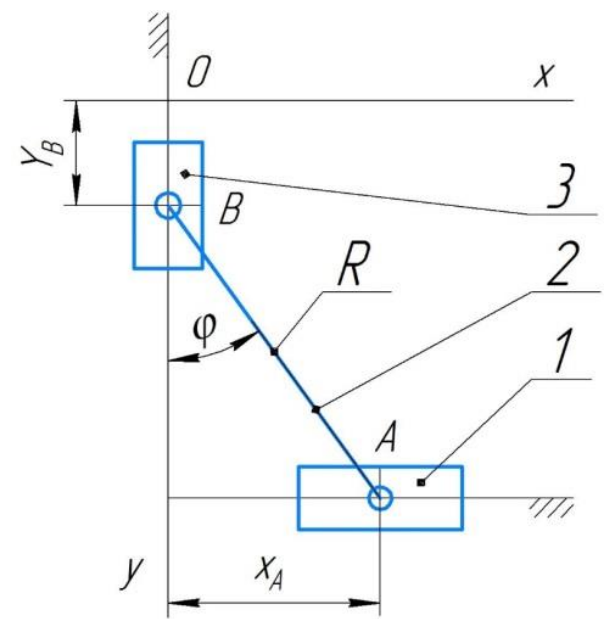

Figure: 2. Structural diagram of the press wedge-joint mechanism with a curving wedge

However, there are also fundamental differences between these mechanisms. The wedge-joint mechanism has short links, and therefore - greater rigidity, its rotary joints are distinguished by large supporting areas capable of transmitting large forces. These differences provide the advantages of a wedge-joint mechanism over link mechanisms when used in forging equipment.

The wedge-joint mechanism includes three movable links and four kinematic pairs of the class 5 (two rotational and two translational ones). Since the mechanism is flat, its mobility is determined by the Chebyshev's formula:

$$
W=2 \cdot n-2 \cdot p_{5}-p_{4}=3 \cdot 3-2 \cdot 4-0=1,
$$

where $n$ - number of moving links of the mechanism,

$p_{5}$ - number of kinematic pairs of class 5 ,

$p_{4}$ - number of kinematic pairs of class 4 .

Therefore, to obtain the certainty of the mechanism links motion, it is necessary to set one independent motion for the input link (wedge 1). Let's divide the mechanism into the primary mechanism and the Assur structural group (Fig. 3). The formula for its structure is: $I(0,1) \rightarrow I I(2,3)_{2,2}$. Consequently, the wedge-joint mechanism is the mechanism of class 2 .

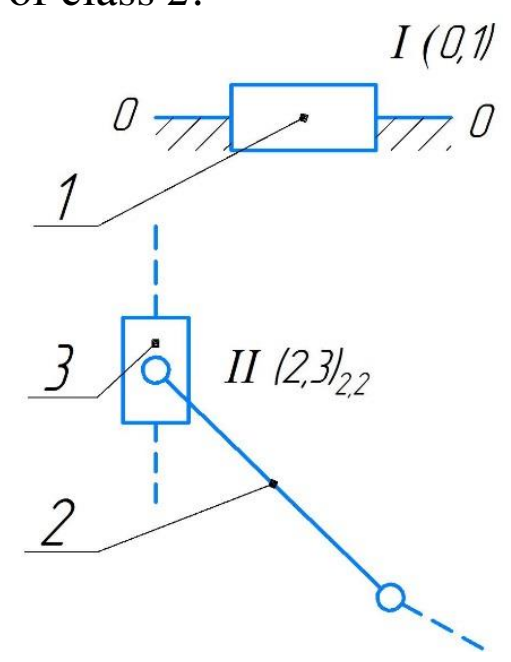

Figure: 3. Structural analysis of the wedge-joint mechanism with a curving wedge in the press 
Let's define the basic relation between the geometric parameters of the wedgejoint mechanism. To do this, consider the mechanism in a random position (see Fig. 2). Place the origin of coordinates at the $\mathrm{B}$ starting point (when points $\mathrm{A}$ and $\mathrm{B}$ are on the same vertical). Let the wedge 1 moves by the stroke $X_{A}\left(X_{A}=h_{h}\right)$. In this case, the link $A B$ deviates from the vertical by the angle $\varphi$, which is a variable angle of the joint 2 . Then the movement of the slide 3 :

$$
Y_{B}=R-R \cdot \cos \varphi=R(1-\cos \varphi) ; Y_{B}=h_{V} .
$$

You can also get a relation establishing a link between $h_{h}$ и $h_{V}$ :

$$
h_{V}=R-\sqrt{R^{2}-h_{h}^{2}}
$$

The relation between the wedge stroke $h_{h}$ and the angle $\varphi$ has the form:

$$
\varphi=\arcsin \left(h_{h} / R\right) \text {. }
$$

Let's perform a kinematic analysis of the wedge-joint mechanism using the analytical method and determine the relation between the speeds and accelerations of the input (wedge 1) and output (slide 3) links. To do this, differentiating formula (2) with respect to time, we find the speed of the slide 3 :

$$
V_{B}=d Y_{B} / d t=R \cdot \sin \varphi \cdot(d \varphi / d t)=R \cdot \sin \varphi \cdot \omega_{2} .
$$

To determine the angular velocity of the joint 2 , we differentiate formula, reducing it to the form $\sin \varphi=X_{A} / R$ and then we obtain:

where

$$
\cos \varphi \cdot d \varphi / d t=V_{A} / R
$$

$$
\omega_{2}=d \varphi / d t=V_{A} /(R \cdot \cos \varphi) .
$$

Substituting this value into the slide speed formula, we obtain

$$
V_{B}=R \cdot \sin \varphi \cdot V_{A} /(R \cdot \cos \varphi)=V_{A} \cdot \operatorname{tg} \varphi
$$

Differentiating formula (8) in time, we find the acceleration of the slide:

$$
a_{B}=d V_{B} / d t=a_{A} \cdot \operatorname{tg} \varphi+V_{A} \cdot 1 / \cos ^{2} \varphi \cdot d \varphi / d t=a_{A} \cdot \operatorname{tg} \varphi+
$$
$V_{A}^{2} /\left(\cos ^{3} \varphi \cdot R\right)$.

We carry out a kinematic study of the wedge-joint mechanism by the graphical-analytical method, thereby checking the results obtained using the analytical method. For this, we construct a plan of the mechanism speeds in the considered position (Fig. 4, a). The speed of the wedge, and consequently the speed of the point A, is directed horizontally and is determined by the used wedge drive. To determine the speed of the point $\mathrm{B}$, and the speed of the slide, we will graphically solve the vector equation:

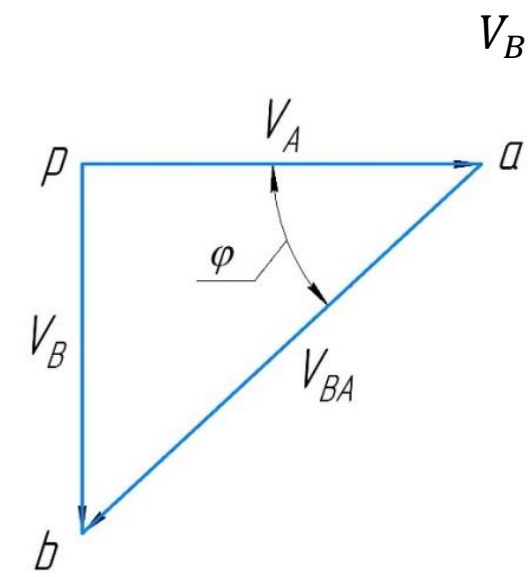

a 
Fig. 4. Kinematic analysis of the wedge-joint mechanism with a curving wedge by the graphic-analytical method: $a$ - speeds plan; $b$ - acceleration plan

We find from the speed plan that

$$
V_{B}=V_{A} \cdot \operatorname{tg} \varphi \text {. }
$$

The resulting formula completely coincides with the previously obtained result (8).

Relative speed

$$
V_{B A}=V_{A} / \cos \varphi .
$$

Then the angular velocity of the joint 2 :

$$
\omega_{2}=V_{B A} / R=V_{A} /(R \cdot \cos \varphi) .
$$

Formulas (7) and (13) coincide.

Let's construct a plan for the wedge-joint mechanism acceleration (Fig. 4, b), assuming that the wedge acceleration, and hence the acceleration of the point $\mathrm{A}$, are known both in magnitude and directionally. We write down and solve graphically the vector equation for determining the slide acceleration:

where $a_{B A}^{n}=\omega_{2}^{2} \cdot R=V_{A}^{2} /\left(R \cdot \cos ^{2} \varphi\right)$.

$$
a_{B}=a_{A}+a_{B A}^{n}+a_{B A}^{\tau},
$$

Drawing an auxiliary horizontal line $n_{2} k$ through the point $n_{2}$, we obtain:

$$
a_{B}=\pi b=\pi k+k b,
$$

$$
\begin{aligned}
& \text { where } \pi k=a_{B A}^{n} \cdot \cos \varphi=V_{A}^{2} /(R \cdot \cos \varphi), \\
& \quad k b=k n_{2} \cdot \operatorname{tg} \varphi=\left(a_{A}+a_{B A}^{n} \cdot \sin \varphi\right) \cdot \operatorname{tg} \varphi= \\
& =\left(a_{A}+V_{A}^{2} /\left(R \cdot \cos ^{2} \varphi\right) \cdot \sin \varphi\right) \cdot \operatorname{tg} \varphi=\left(a_{A}+V_{A}^{2} /(R \cdot \cos \varphi) \cdot \operatorname{tg} \varphi\right) \cdot \operatorname{tg} \varphi .
\end{aligned}
$$

So, the acceleration of the slide 3

$$
\begin{gathered}
a_{B}=V_{A}^{2} /(R \cdot \cos \varphi)+a_{A} \cdot \operatorname{tg} \varphi+V_{A}^{2} /(R \cdot \cos \varphi) \cdot \operatorname{tg}^{2} \varphi= \\
=V_{A}^{2} /(R \cdot \cos \varphi) \cdot\left(1+\operatorname{tg}^{2} \varphi\right)+a_{A} \cdot \operatorname{tg} \varphi=V_{A}^{2} /\left(R \cdot \cos ^{3} \varphi\right)+a_{A} \cdot \operatorname{tg} \varphi .
\end{gathered}
$$

Formulas (9) and (17) coincide and, therefore, the kinematic calculations of the wedge-joint mechanism are performed correctly.

The power analysis of the wedge-joint mechanism is carried out by constructing friction circles similarly to the method of determining the kinetostatic characteristics for toggle presses, taking the following assumptions: the counterbalance force ensures that the joints in the links and the wedge coupling with the upper plate do not open; we neglect the weight and inertial forces of the mechanism links, since they are relatively small and taking them into account insignificantly affects the final result; the friction coefficients in the joints and the friction coefficients in the wedge guides and slide are equal to each other,.

A diagram of the forces operating in a real wedge-joint mechanism is shown in the Fig. 5, a. Friction in translational kinematic pairs is taken into account by the fact that the normal pressure force deviates from the normal to the surface by the friction angle $\rho(\operatorname{tg} \rho=f)$. Let's consider the resulting rotary joint force $F_{A B}=F_{23}$.

The $F_{A B}$ force is directed tangentially to the friction circles located in the cylindrical surfaces centers of the wedge and rotary joint. The total angle of the force tilt $F_{A B}$ to the vertical makes $(\varphi+\psi)$. The angle $\psi$ takes into account the friction losses between the mating pairs "wedge-rotary joint " and "rotary joint-slide". The expres- 
sion for determining the value of this angle is found from the right-angled triangle $\mathrm{ABC}$ :

$$
\sin \psi=f \cdot(R+r) / R .
$$

Let's consider the balance of the slide 3 . It is under effect of the forces $F_{03}$ and $F_{23}$ from the side of the discarded links and the force of the useful resistance $F_{V}$. The equilibrium equation for the link 3 has the form

$$
F_{V}+F_{03}+F_{23}=0
$$

where $F_{23}=F_{A B}$. Having constructed a closed force triangle for these forces (Fig. 5, b), we write, according to the theorem of sines, the relation between them:

$$
F_{V} / \sin \left(90^{\circ}-\varphi-\rho-\psi\right)=F_{23} / \sin \left(90^{\circ}+\rho\right) .
$$

Let's consider the equilibrium of the link 2 , taking into account that $F_{32}=$ $-F_{23}$ :

$$
F_{32}+F_{12}=0 \text {, whence } F_{12}=-F_{32} .
$$
en by:

Equilibrium equation of the link 1 , taking into account that $F_{21}=-F_{12}$, is giv-

$$
F_{21}+F_{01}+F_{h}=0 \text {. }
$$

This equation is also solved by forces scheduling (see Fig. 5 , b). Using the theorem of sines, we get:

$$
F_{h} / \sin (\varphi+\rho+\psi)=F_{21} / \sin \left(90^{0}-\rho\right) .
$$

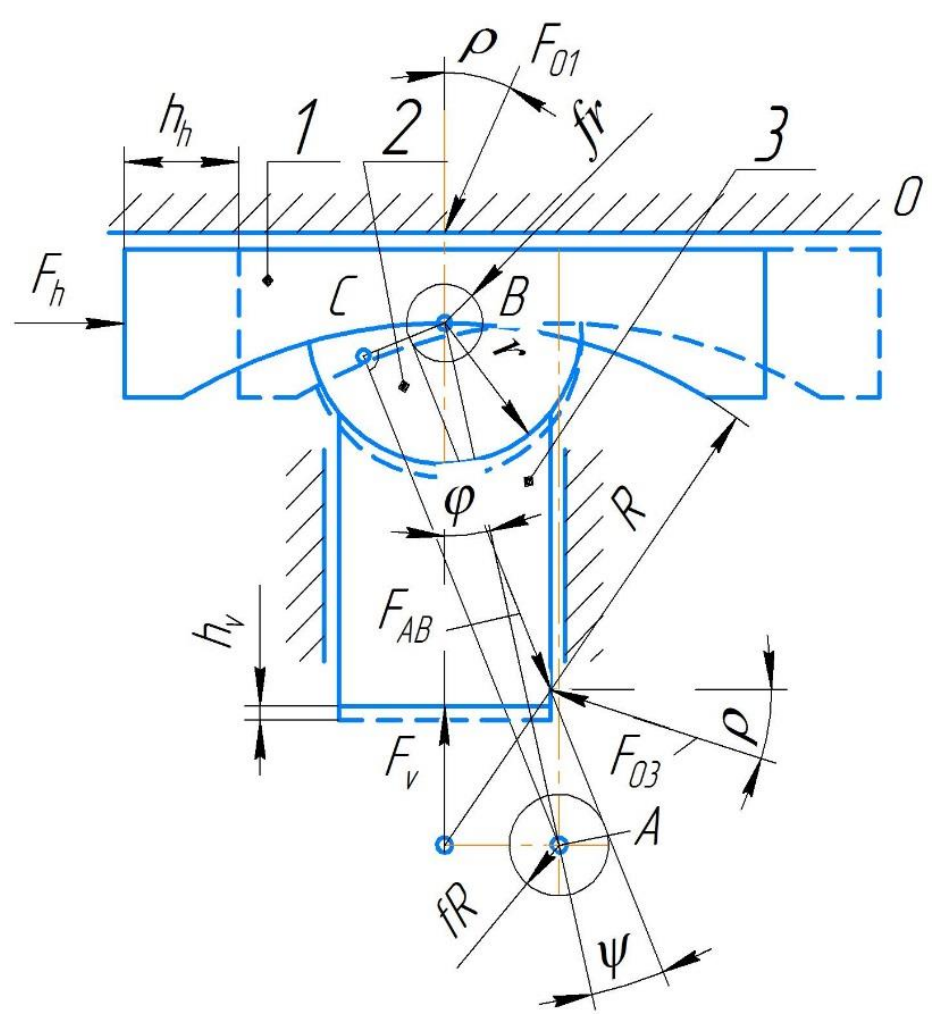

a 

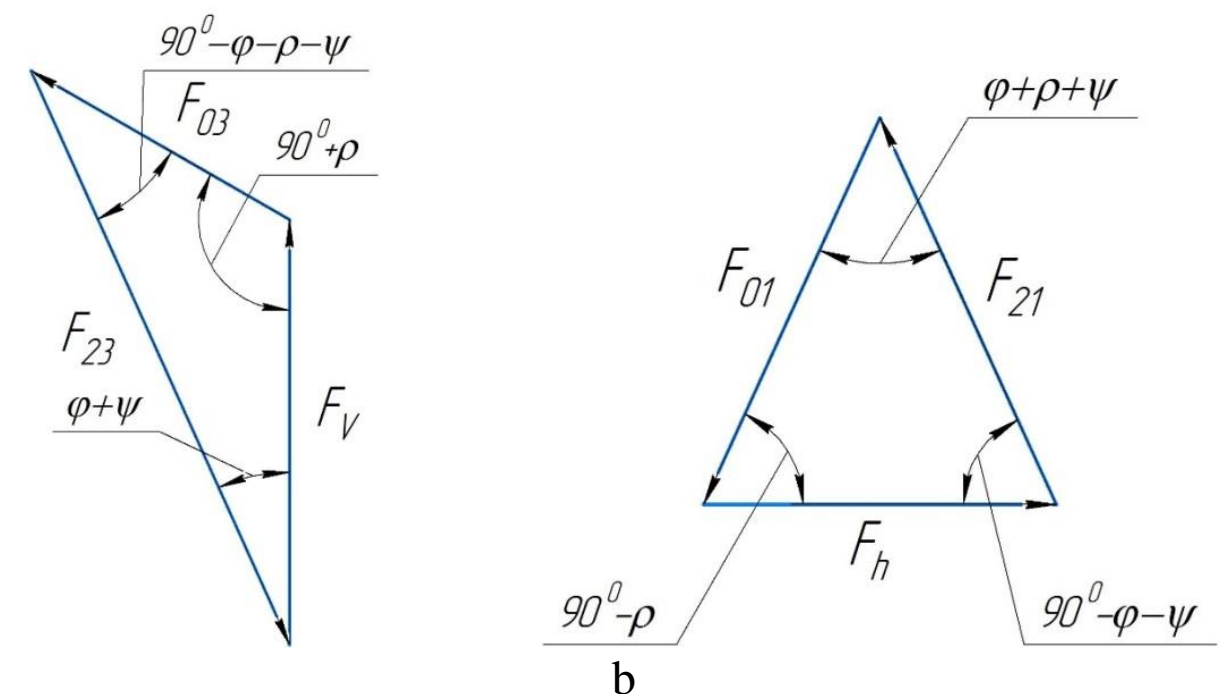

Figure: 5. Force analysis of a wedge-joint mechanism with a curving wedge: a - design diagram; $b$ - forces plans

From the considered equilibrium equations of the wedge-joint mechanism links, it can be concluded that the forces $F_{23}, F_{32}, F_{12}, F_{21}$ are identical to modulo. Therefore, in order to find the ratio between the driving force $F_{h}$ and the force of the useful resistance $F_{V}$, it is necessary to express the forces $F_{23}$ и $F_{21}$ from the equations (20), (23), and equate the obtained expressions. Then we get:

$$
F_{h} \cdot \sin \left(90^{\circ}-\rho\right) / \sin (\varphi+\rho+\psi)=F_{V} \cdot \sin \left(90^{\circ}+\rho\right) / \sin \left(90^{\circ}-\varphi-\rho-\psi\right) \text {. }
$$

Using trigonometric dependencies:

$$
F_{h} \cdot \cos \rho / \sin (\varphi+\rho+\psi)=F_{V} \cdot \cos \rho / \sin (\varphi+\rho+\psi) \text {. }
$$

Therefore, the required relation:

$$
\begin{gathered}
F_{V}=F_{h} / \operatorname{tg}(\varphi+\rho+\psi)= \\
=F_{h} / \operatorname{tg}(\varphi+\operatorname{arctg} f+\arcsin (f \cdot(R+r) / R)) .
\end{gathered}
$$

Let's consider the analytical analysis of a wedge-joint mechanism with a curving wedge, based on the compilation of equilibrium equations. For the calculation by the analytical method, we represent the wedge-joint mechanism in the form of the two-slide link mechanism (Fig. 6). We begin the force analysis by considering the structural group 1-2. 


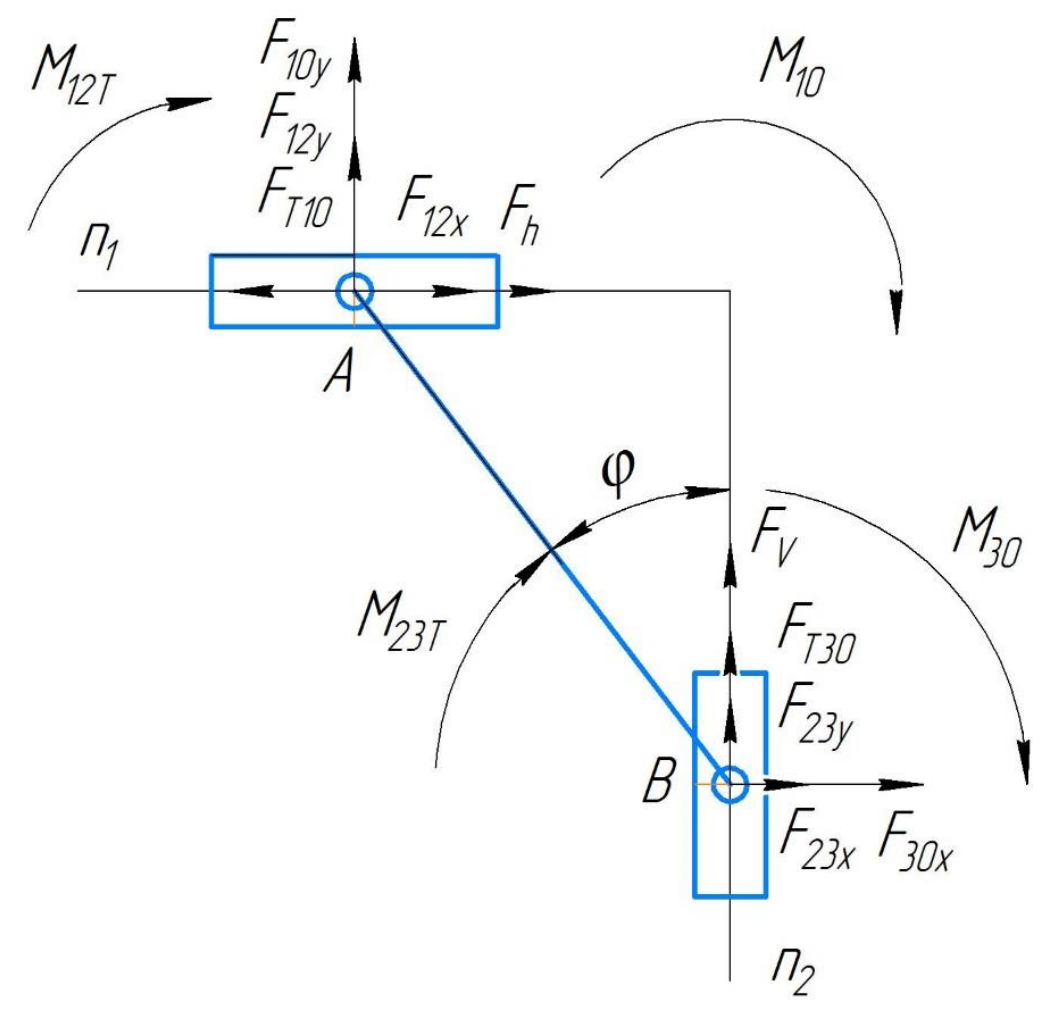

Figure: 6. Analytical model of loading a wedge-joint mechanism with a curving wedge

Below there is a system of equilibrium equations including the frictional forces in the translational pair and the friction moments in the rotational one

$$
\begin{aligned}
\sum M_{A}\left(F_{i}\right)_{2}= & 0: M_{21 T}+M_{23 T}+F_{23 x} \cdot\left(Y_{A}-Y_{B}\right)-F_{23 y} \cdot\left(X_{A}-X_{B}\right)=0 \\
& \sum\left(F_{i x}\right)_{1}=0: F_{12 x}+F_{h}+F_{T 10}=0 \\
& \sum\left(F_{i y}\right)_{1}=0: F_{12 y}+F_{10 y}=0 \\
& \sum\left(F_{i x}\right)_{2}=0:-F_{12 x}+F_{23 x}=0 \\
& \sum\left(F_{i y}\right)_{2}=0:-F_{12 y}+F_{23 y}=0 \\
& \sum M_{A}\left(F_{i}\right)_{1}=0: M_{10}+M_{12 T}=0
\end{aligned}
$$

where $F_{12 x}, F_{12 y}, F_{23 x}, F_{23 y}$ - reactions in the rotary joints;

$F_{10 y}$ - reaction in the translational pair;

$F_{T 10}$-frictional force in the translational pair;

$F_{h}$ - force applied to the wedge;

$M_{12 T}=-M_{21 T}, M_{23 T}=-M_{32 T}$ - friction moments in rotational pairs, which can be represented in the form of the following dependencies:

$$
\begin{gathered}
M_{23 T}=-\sqrt{F_{23 x}^{2}+F_{23 y}^{2}} \cdot f_{B} \cdot r_{B} \cdot \operatorname{sign}\left(\varphi_{2}^{\prime}\right) ; \\
M_{12 T}=-\sqrt{F_{12 x}^{2}+F_{12 y}^{2}} \cdot f_{A} \cdot r_{A} \cdot \operatorname{sign}\left(\varphi_{2}^{\prime}\right) ; \\
F_{T 10}=-\left|F_{10 y} \cdot f_{n 1}\right| \cdot \operatorname{sign}\left(X_{1}^{\prime}\right),
\end{gathered}
$$

where $r_{A}, r_{B}$ - wedge radii;

$f_{A}, f_{B}, f_{n 1}-$ friction coefficients; 
$\varphi_{2}^{\prime}, X_{1}^{\prime}$ - first-order dynamic characteristics.

As a result of solving the system of equations (27 - 32) taking into account (33 - 35), reactions in kinematic pairs, friction forces and moments can be determined. To solve nonlinear systems of equations (27 - 35), Newton's method was used. Knowing the reactions $F_{23 x}, F_{23 y}$ the force of the useful resistance $F_{V}$ was determined, from the equilibrium condition of the link 3 :

$$
\begin{array}{r}
\sum\left(F_{i x}\right)_{3}=0: F_{30 x}-F_{23 x}=0 ; \\
\sum\left(F_{i y}\right)_{3}=0: F_{T 30}-F_{23 y}+F_{V}=0 ; \\
\sum M_{B}\left(F_{i}\right)_{3}=0: M_{32 T}+M_{30}=0,
\end{array}
$$

where $F_{V}$ - useful resistance force;

$F_{T 30}$ - friction force in the translational pair, which can be represented as the following relation:

$$
F_{T 30}=-\left|F_{30 x} \cdot f_{n 2}\right| \cdot \operatorname{sign}\left(Y_{3}^{\prime}\right),
$$

where $f_{n 2}$ - friction coefficient in the translational pair;

$Y_{3}^{\prime}$ - first-order dynamic characteristic.

The Fig. 7 shows the diagrams of changes in the force $F_{V}$ depending on the turning angle of the link (rotary joint) $\varphi$ for different values of the friction coefficients $f$, calculated by two methods

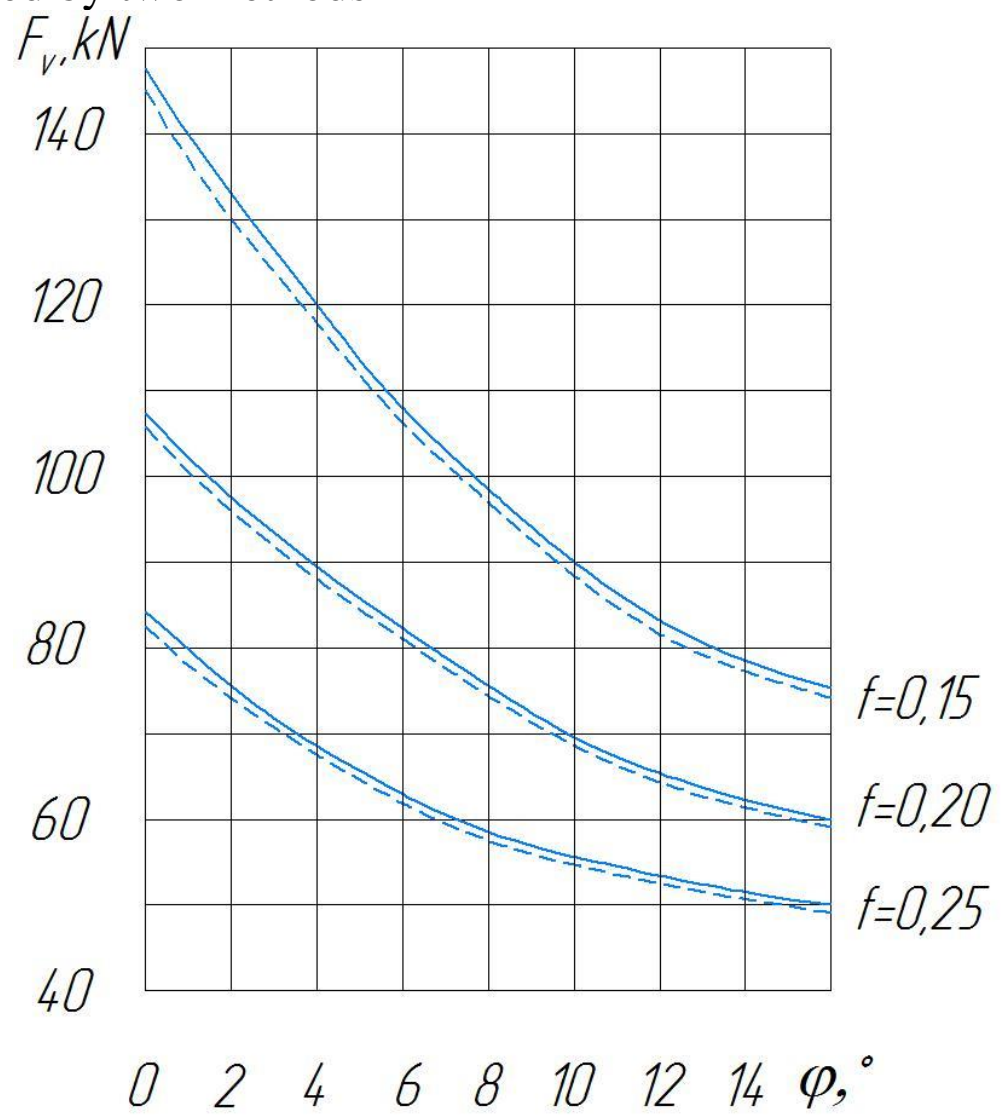

Figure: 7. Diagram of the effective resistance force change from the turning angle of the link:

- - - graphic-analytical method; analytical method

Parameters of the wedge-joint mechanism: wedge radius $R=300 \mathrm{~mm}$; link radius $r=45 \mathrm{~mm}$; wedge force $F_{h}=49 \mathrm{kN}$; the angle $\varphi$ is changed from $0^{0}$ to $15^{0}$. 
The analysis of the obtained data showed that the discrepancy between the results obtained by the two methods is not more than $2.5 \%$, which indicates the possibility of their application. The graphical-analytical method is simpler and more intuitive to use, however, it is applicable only for link mechanisms, while the analytical method is more universal.

To implement the developed mathematical models, the program was compiled. It allows to calculate the geometric, kinematic and force parameters of presses with a wedge-joint mechanism with a curving wedge. To put that into perspective, dependency diagrams of geometric and power characteristics are combined, which allows to choose rational parameters of this mechanism (Fig. 8). 


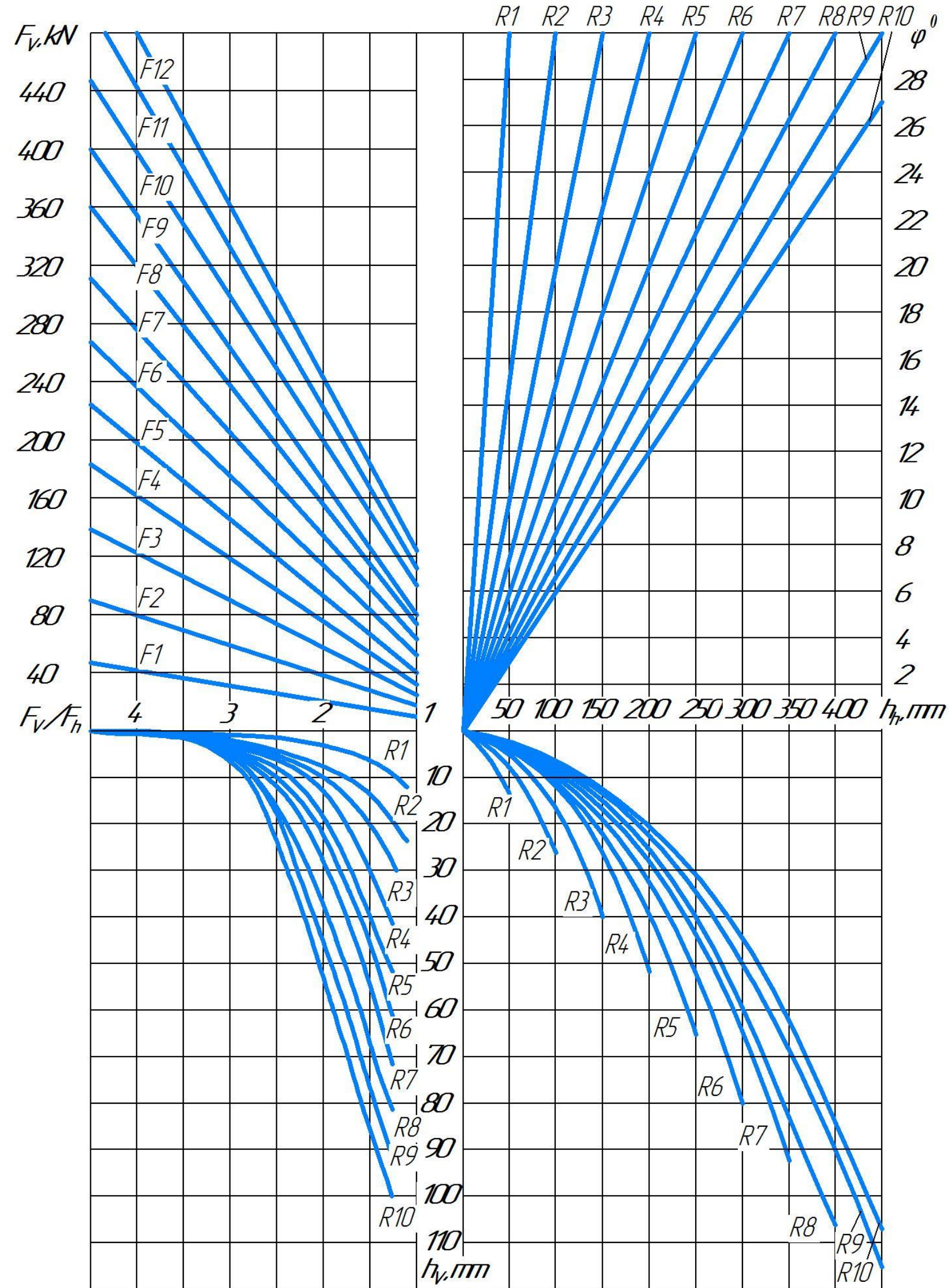

Figure: 8. Diagrams for determining the geometric and power parameters of the wedge-joint mechanism with a curving wedge

$$
\begin{gathered}
R_{1} \ldots R_{10}=100 \mathrm{~mm} \ldots 1000 \mathrm{~mm} \text { at a pitch of } 100 \mathrm{~mm} ; F_{1} \ldots F_{12}= \\
10 \mathrm{kN} \ldots 120 \mathrm{kN} \text { at a pitch of } 10 \mathrm{kN}
\end{gathered}
$$


The calculations were carried out at $f=0,1$. With a known technological force on the slide $F_{V}$, the slide stroke $h_{V}$ and the desired gain in force $F_{V} / F_{h}$, it is possible to determine the turning angle of the link $\varphi$, as well as the parameters of the driving wedge: radius $R$ and stroke $h_{h}$. You can also solve the inverse problem: using the known values of the geometrical parameters of the drive wedge $R$ and $h_{h}$, it is possible to determine the turning angle of the link $\varphi$, the working stroke of the slide $h_{V}$ and the force ratio $F_{V} / F_{h}$, and then, knowing or setting a certain value of the drive force $F_{h}$, we determine the corresponding working force on the slide $F_{V}$. For example, with the known values: cutting with a shift force $F_{V}=160 \mathrm{kN}$ (the billet with the diameter $d=30 \mathrm{~mm}$ from steel 45) and the recommended cutting stroke at which the billet is separated $\left(h_{V}=3,3 \mathrm{~mm}\right)$, the desired ratio $F_{V} / F_{h}=2,5$, we have: $F_{h}=$ $64 \mathrm{kN}, h_{h}=36 \mathrm{~mm}, R=200 \mathrm{~mm}, \varphi=10,4^{0}$.

Thus, the use of diagrams (see Fig. 8) makes it possible to select, according to the value of the technological separation force, all the geometric, kinematic and power parameters of equipment with a wedge-joint mechanism with a curving wedge.

To confirm the theoretical calculations, experimental studies were carried out on the unit (Fig. 9), which consists of side plates 1, 2, connected by bolts 3 with nuts 4. On the bolts 3 there is an intermediate plate 5 with a fixed slide 6 , in the dap of which there is the link 7 with radius $r$, supported by the wedge 8 , having a curving surface with a radius $R$. On the plate 2, the traverse 9 is fixed, to which the drive hydraulic cylinder 10 is attached, the rod of it rests against the wedge 8 . On the plate 1 , the sleeve-type knives 11 are installed, that contact with the upper half-sleeve knife 12 by flat cutting edges, fixed on the intermediate plate 5 . The additional wedge 13 with a constant wedge angle is installed in the dap of the slide 6 , it rests on the plate 5 . The wedge 13, which is moved by the bolt 14 , serves for clearance adjustment in the wedge joint mechanism. Springs 15 are installed between the plates 1 and 5. The installation works as follows. The sample 16 is installed in the sleeve-type knives 11. The bolt 14 moves the wedge 13, choosing the clearances and elastically deforming the parts that make up the power circuit of the installation: plates, slide, link, wedge, bolts. After that, pressure is supplied to the drive cylinder 10, the rod of which begins to move the wedge 8 . The wedge 8 effects the link 7 , which rotates and moves the slide 6 , the plate 5 and the knife 12 , cutting off the billet with a shift. The installation returns to its original position under the action of springs 15 .

Experimental unit parameters: $\mathrm{R}=300 \mathrm{~mm}, \mathrm{r}=45 \mathrm{~mm}$. The useful resistance force $F_{V}$ was created by cut with a shift billets with the diameter of $10 \mathrm{~mm}$ and the length of $40 \mathrm{~mm}$ from steel. In order to minimize such factors as the stamp, billet, knives bending, the cut was carried out according to a symmetrical, two-cut scheme (see Fig. 9). The force parameters were measured using the method of strain gauging with the sensors gluing on the upper semi sleeve-type knife 12 and the rod of the hydraulic cylinder 10. Foil resistive strain gages FKTK 10 - $200 \mathrm{C}$ - 1 were used. The base of the sensors was $10 \mathrm{~mm}$, the resistance was $200 \mathrm{Ohm}$. The sensors were glued using standard technology. The signal from the sensors was intensified with a Topaz3-01 device and fed to the $\mathrm{N}-115$ oscilloscope loop. The movement of the working bodies was recorded by the rheostatic indicator of displacement. 


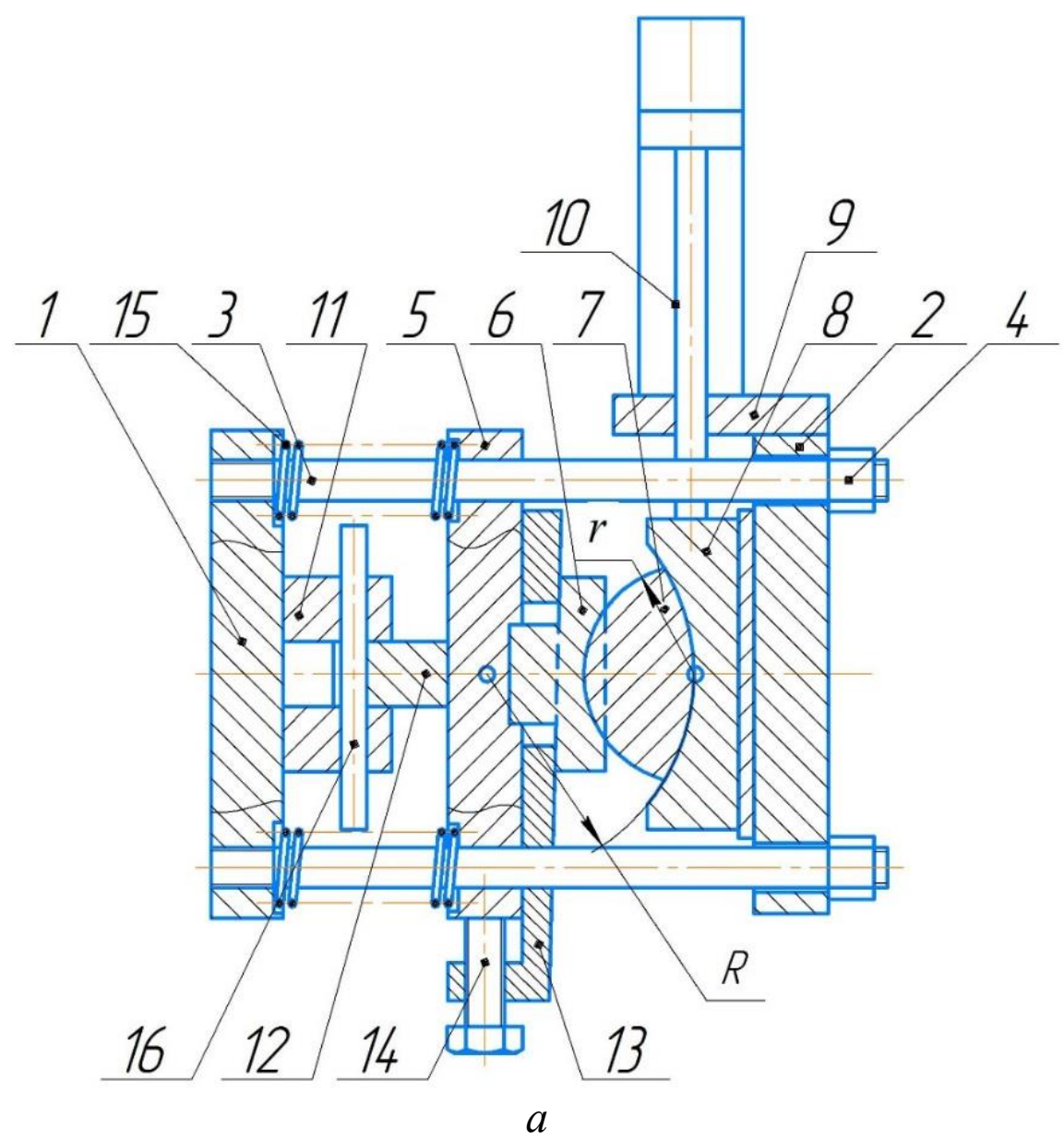

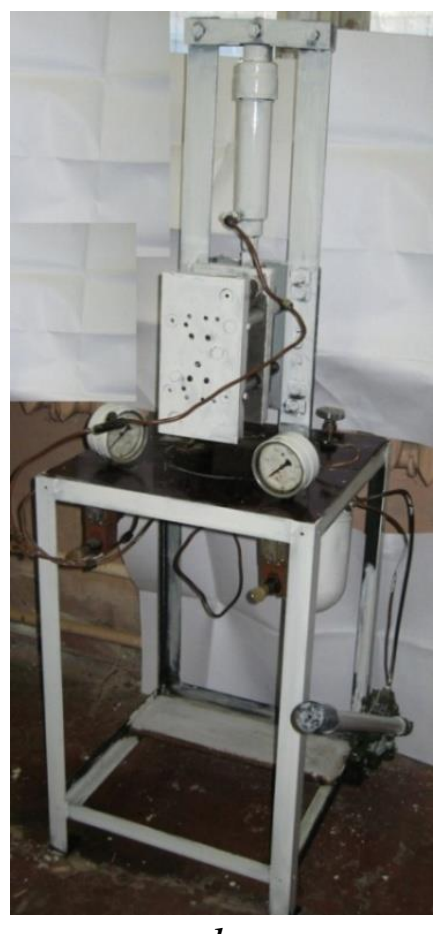

$b$

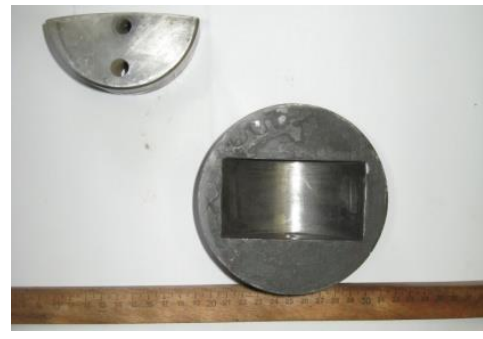

$c$

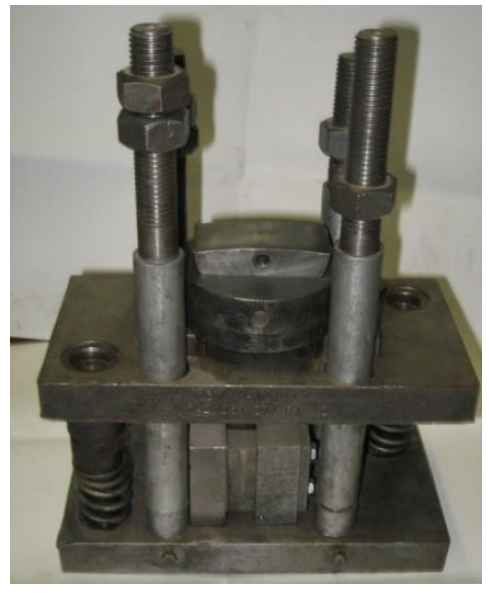

$d$

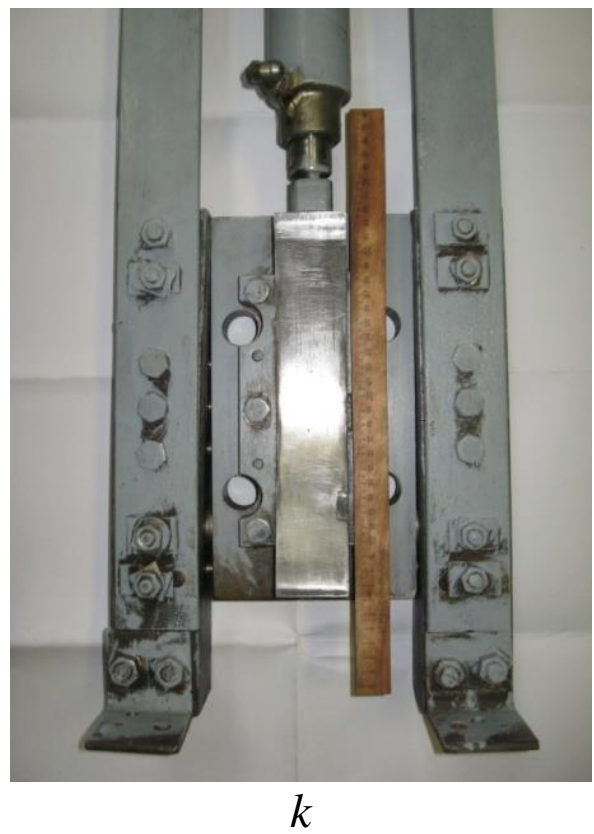

Figure: 9. Construction (a) and photographs of the experimental unit: $b$ - complete unit; $c$ - link and slide; $d$ - cutting node; $k$-drive wedge in guides

The Fig. 10 shows a typical oscillogram for recording forces and motions: 1 motion $h_{V}$ of the upper semi sleeve-type knife $12 ; 2$ - force $F_{h}$ developed by the cylinder; 3 - vertical force F_V (cutting force) on the upper half-sleeve knife. 


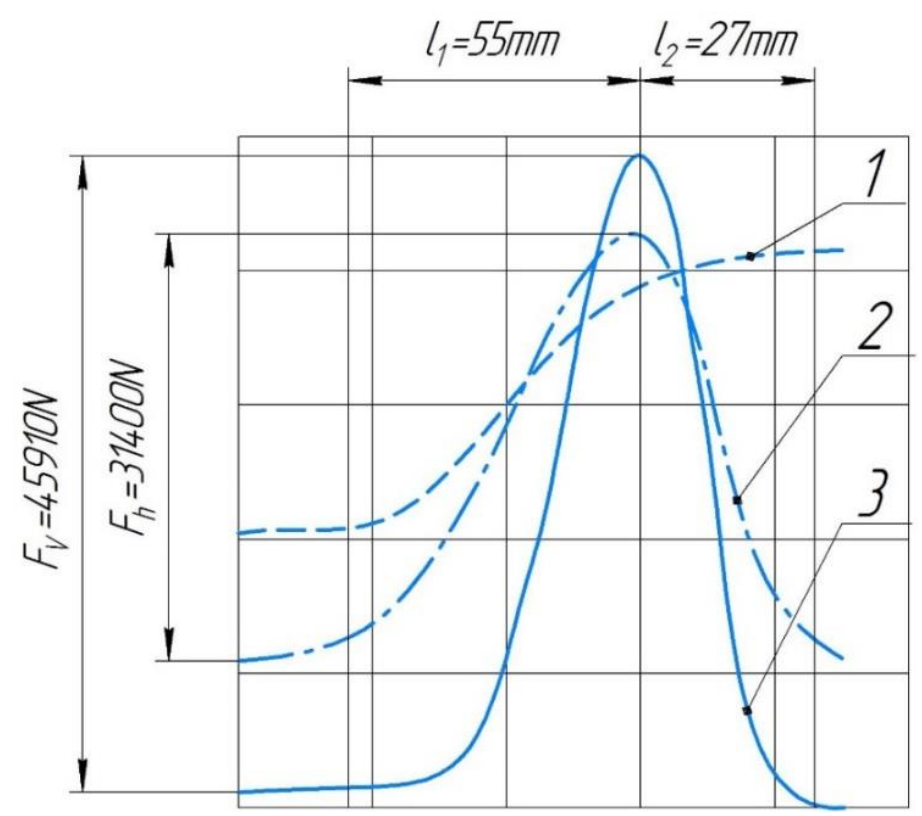

Figure: 10. Typical oscillogram

The analysis of the oscillogram shows that the stroke of the wedge $l_{1}$ horizontal movement occurs after the elastic deformation part sampling with the help of the wedge 13 (see Fig. 9, a), that has a wedging fixed angle. After the start of the wedge with a curving surface movement, the process of elastic deformation continues and goes along with the process of introducing the knife into the billet, there is a sharp increase in force to the maximum value of the cut, and then a sharp drop in force (billet shearing distortion). The movement of the wedge continues $\left(l_{2}\right)$ due to the unloading of the unit from elastic deformation. For samples with a diameter of $10 \mathrm{~mm}$ from steel St.3, the cut parameters were: $F_{h}=31400 \mathrm{~N}, F_{V}=45910 \mathrm{~N}, l_{1}=55 \mathrm{~mm}, l_{2}=$ $27 \mathrm{~mm}$. The error between the calculated (see Fig. 8) $F_{V}=48946 \mathrm{~N}$ and the measured $F_{V}=45910 \mathrm{~N}$ values of the rolled products' force does not exceed $7 \%$. The error between the arithmetic mean of 10 equal measurements does not exceed $10 \%$ of the calculated value $F_{V}$.

\section{Discussion of the research results.}

On the basis of the separation processes analysis and equipment for its implementation, the expediency of using a wedge-joint mechanism with a curving wedge in presses for the implementation of metal forming separation processes is substantiated. It's diagram of the deformation force change in time is the closest to the technological typical diagram of the force change during separation. A comparative analysis of typical diagrams of the press-forging plant efforts used for separation operations is shown in the Fig. 11. 


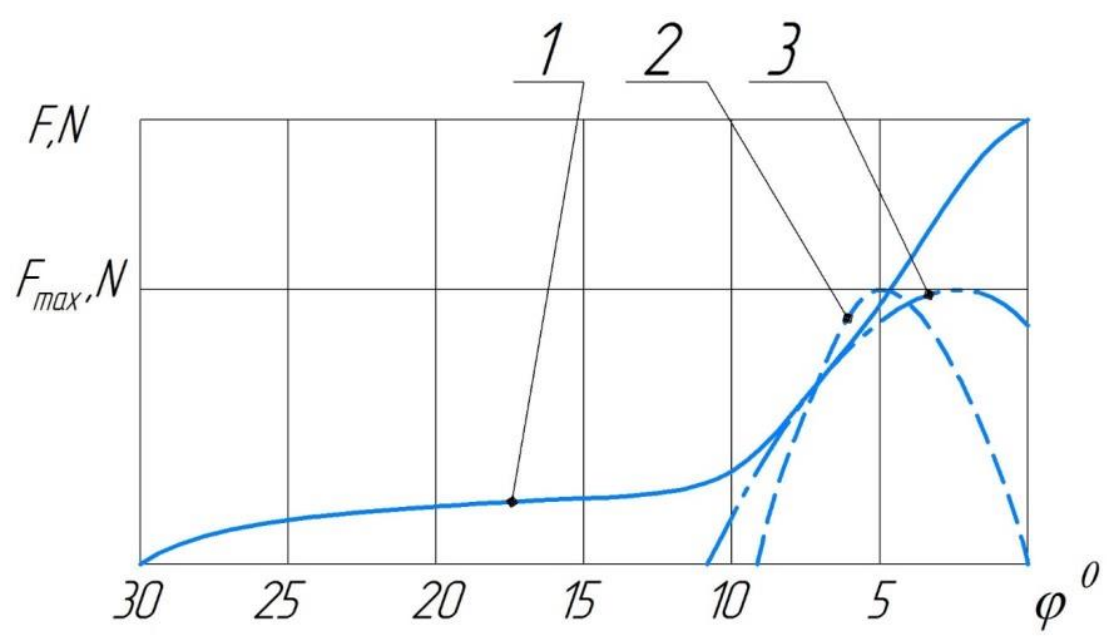

Figure: 11. Typical force diagrams of press-forging plants: 1 - toggle press; 2 - wedge-joint press with a curving wedge; 3 -typical force graph at the cutting with a shift

It has been established that the cutting stroke in the press with a crank-slide operating mechanism (1) begins when the eccentric shaft does not reach the extreme lower position by $5 \ldots 15^{\circ}$. In the press with the wedge-joint mechanism with a curving wedge (2), the cutting stroke starts at $\varphi=0^{\circ}$. Since in the press (1), the contact of the billet during the cutting occurs at a certain speed of the slide, this determines its high dynamics. In this case, in the press (2), the speed at the very beginning of the segment is equal to zero. A press with a wedge-joint mechanism with a curving wedge has large supporting surfaces, a small height of the links in the direction of the working force. If the height of the crank press is taken to be 1 , then the height of the wedge press with a curving wedge will be 0.6 . Thus, the use of a wedge-joint mechanism with a curving wedge in presses ensures less elastic deformation and press dynamics, and the press utilization rate increase.

Mathematical models of the wedge-joint mechanism with a curving wedge, presented in the form of a two-slide link mechanism, have been developed, allowing to carry out its structural, kinematic and dynamic analysis. Based on the analysis of the proposed mathematical models, dependencies were identified and a procedure was developed for calculating the geometric, kinematic and power parameters of presses with the wedge-joint mechanism with a curving wedge.

The results of experimental studies of the kinematic and power parameters of the wedge-joint mechanism with a curving wedge, with regard to the implementation of waste-free methods for separating long products, indicate a sufficient degree of reliability of the developed numerical mathematical models. The error between the calculated and measured values of the forces on the slide does not exceed $10 \%$.

Experimental studies have shown that the value of the elastic deformation of the experimental unit significantly increases the horizontal stroke of the curving wedge. Therefore, it is advisable to use an additional wedge mechanism in a press with the wedge-joint mechanism with a curving wedge to ensure the approach stroke, which makes it possible to reduce the energy consumption for elastic deformation and to extinguish dynamic loads.

\section{Conclusion.}


1. On the basis of the performed analysis of technologies and equipment for separation operations, it was found that the traditional operating mechanisms of press-forging machines cannot create force loading conditions typical for separation processes requiring the provision of maximum technological force at the beginning of the working stroke. In addition, they are multi-link and have a relatively low rigidity. The expediency of using the wedge-joint mechanism with a curving wedge in presses for the implementation of pressure treatment separation processes was substantiated, It's diagrams of the change in the deformation force is the closest to the technological typical diagram of the change in force during separation.

2. The wedge-joint mechanism with a curving wedge has a lower height of parts in comparison with crank mechanisms, which ensures less elastic deformation and press dynamics.

3. The use of the additional wedge mechanism in a press with the wedge-joint mechanism with a curving wedge to ensure the approach stroke is substantiated. This makes it possible to reduce energy consumption for elastic deformation and further reduce dynamic loads. In this case, a press with the wedge-joint mechanism is easier to remove from jamming due to the movement of this additional wedge of a small wedge angle.

4. The mathematical models of the wedge-joint mechanism with a curving wedge, presented in the form of a two-slide link mechanism, allowing its structural, kinematic and dynamic analysis were developed. Based on the analysis of the proposed mathematical models, dependencies have been identified and a method for calculating the geometric, kinematic and power parameters of the wedge-joint mechanism with a curving wedge with regard to separation processes was developed. Comparison of the results of kinematic and dynamic analyzes carried out by analytical and graphic-analytical methods confirms the reliability of the calculations, since their discrepancy is not more than $2.5 \%$.

5. The conducted experimental studies have confirmed the adequacy of the mathematical models. The error between the calculated and measured values of the forces on the slide does not exceed $10 \%$.

\section{Declarations}

\section{Funding}

Not applicable.

Conflicts of interest/Competing interests (include appropriate disclosures)

The authors declare that there is no conflict of interests regarding the publication of our article.

\section{Availability of data and material}

Not applicable.

Code availability (software application or custom code) 
Not applicable

Authors' contributions (optional: please review the submission guidelines from the journal whether statements are mandatory)

By Sergii G. Karnaukh: developed research method.

By Nataly V. Chosta: calculation of the forces ensuring in the stamp

By Oleg E. Markov: force analysis.

By Volodymyr V. Kukhar: literature review.

\section{Ethics approval}

This manuscript was submitted to only one journal. The submitted work is original and do not have been published elsewhere in any form or language (partially or in full). Results have been presented clearly, honestly, and without fabrication, falsification or inappropriate data manipulation (including image based manipulation). Authors adhered to rules for acquiring, selecting and processing data. Data, text and theories were the authors own. Proper acknowledgements to other works were be given and summarized.

\section{Consent to participate}

Not applicable.

\section{Consent for publication}

Not applicable.

\section{References}

1. Ranjan, S., Jha, V.K. \& Pal, P. Application of emerging technologies in ERP implementation in Indian manufacturing enterprises: an exploratory analysis of strategic benefits. Int J Adv Manuf Technol 88, 369-380 (2017). https://doi.org/10.1007/s00170-016-8770-6.

2. Lisunets, N.L. Usage of physical and mathematical simulation for improvement of the processes of metal shear cutting. CIS Iron and Steel Review, 2019, 17, P. 34-38.

https://www.scopus.com/authid/detail.uri?authorId=6508354482.

3. Lisunets, N.L. Improving the efficiency of the processes of billets manufacture from rolled metal via shift cutting based on simulation. Chernye Metally, 2018, (6), P. 31-35. 
4. Karnaukh, S.G., Markov, O.E., Aliieva, L.I., Kukhar, V.V. Designing and researching of the equipment for cutting by breaking of rolled stock. International Journal of Advanced Manufacturing Technology. 2020.

5. Karnauh, S., Karnaukh, D. Research of the influence of deformation speed on energy and power adjectives of the process of three-point cold bend breaking and on alignment integrity of raw parts. Metallurgical and Mining Industry. 2011.

6. Karnaukh, S.G. Studying the process of static-dynamic loading of a preform according to the scheme of three-point breaking by bending in press-hammers. Kuznechno-Shtampovochnoe Proizvodstvo (Obrabotka Metallov Davleniem), 2001.

7. Tian, Y., Zou, H. \& Guo, W. An integrated knowledge representation model for the computer-aided conceptual design of mechanisms. Int J Adv Manuf Technol 28, 435-444 (2006). https://doi.org/10.1007/s00170-004-2399-6.

8. Mull, J., Durand, C., Baudouin, C. et al. A new tailored solution to predict blow efficiency and energy consumption of hammer-forging machines. Int $\mathbf{J}$ Adv Manuf Technol (2020).

9. Chehab AG, El Naggar MH (2003) Design of efficient base isolation for hammers and presses. Soil Dyn Earthq Eng 23: 127141. https://doi.org/10.1016/S0267-7261(02)00157-4.

10.Jomartov A, Tuleshov A, Kuatova M (2020) Dynamic model of a crank press in the process of braking. B: Kuo C-H, Lin P-C, Essomba T, Chen G-C (eds) Robotics and Mechatronics. Springer International Publishing, Cham, P. 141150.

11.Won, C., Lee, W., Lee, H. et al. Effect of two-stage press blanking on edge stretchability with third-generation advanced high-strength steels. Int $\mathbf{J} \mathrm{Adv}$ Manuf Technol 110, 13-27 (2020). https://doi.org/10.1007/s00170-020-058541 .

12.Telegin, V.V., Kozlov, A.M., Sakalo, V.I.S olid Modeling and Dynamic Analysis of Mechanisms of Press-forging Machines. Procedia Engineering, 2017, 206, p. 1258-1263.

13.Telegin, V., Kozlov, A. Computer realization of research into the dynamics of mechanical systems. IOP Conference Series: Materials Science and Engineering, 2016, 124(1). 
Figures

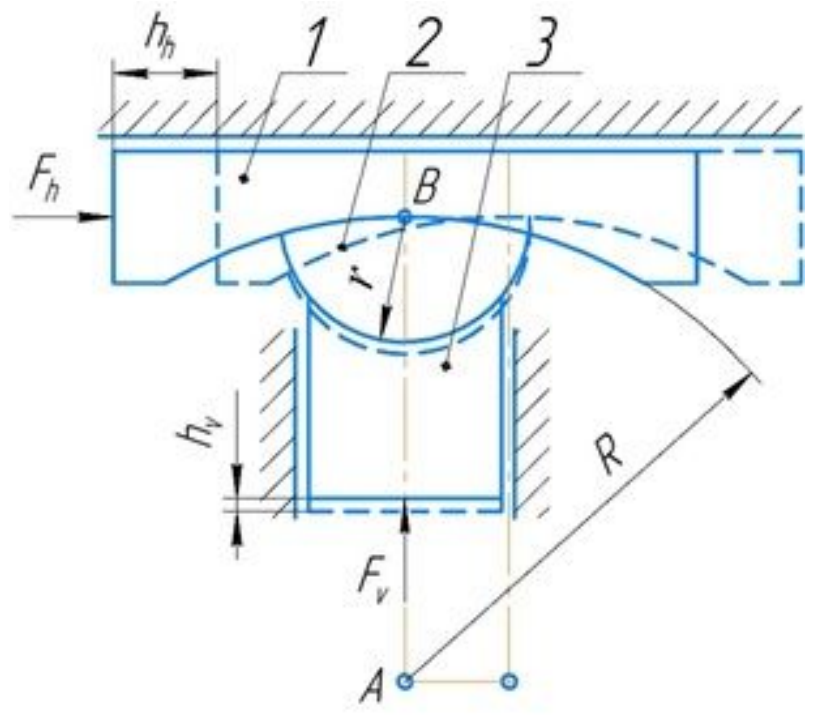

\section{Figure 1}

Scheme of a wedge-joint mechanism with a curving wedge

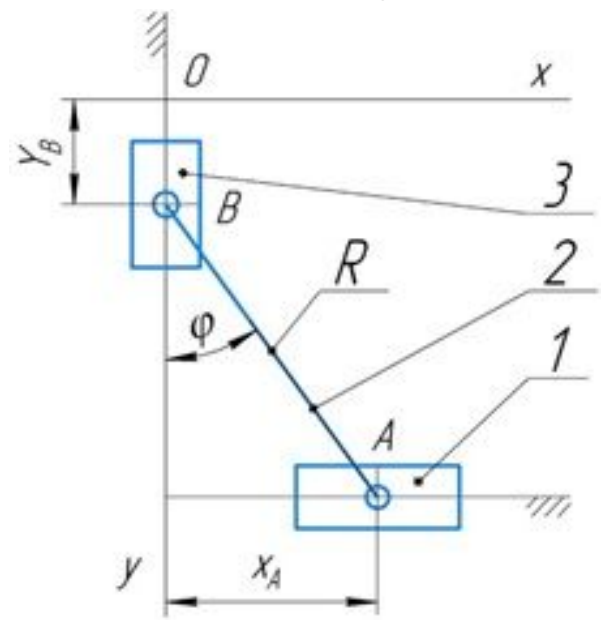

\section{Figure 2}

Structural diagram of the press wedge-joint mechanism with a curving wedge 


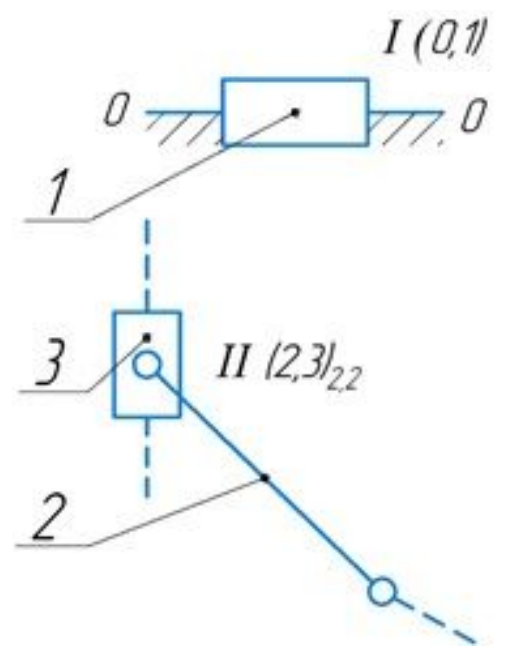

Figure 3

Structural analysis of the wedge-joint mechanism with a curving wedge in the press

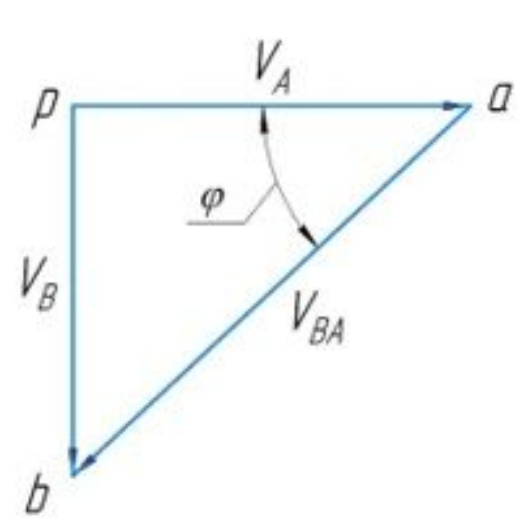

a

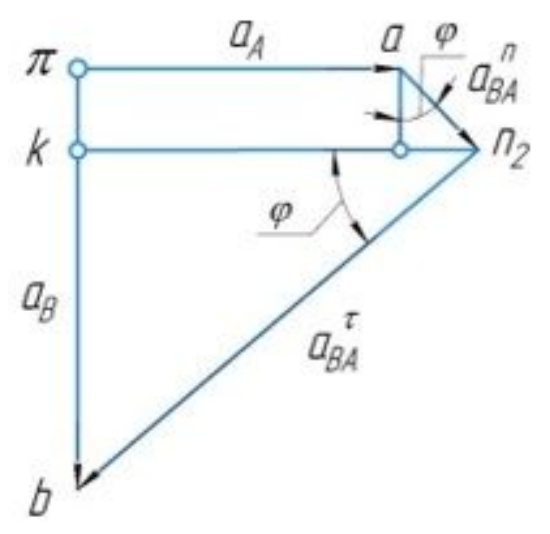

b

\section{Figure 4}

Kinematic analysis of the wedge-joint mechanism with a curving wedge by the graphic-analytical method: $a$ - speeds plan; $b$ - acceleration plan 


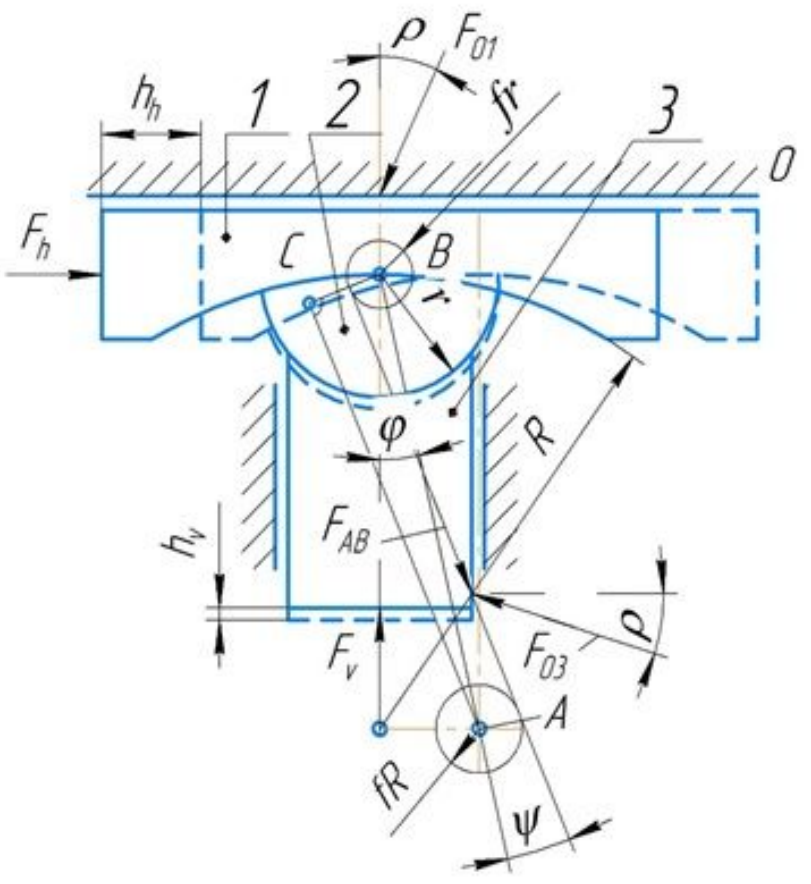

a
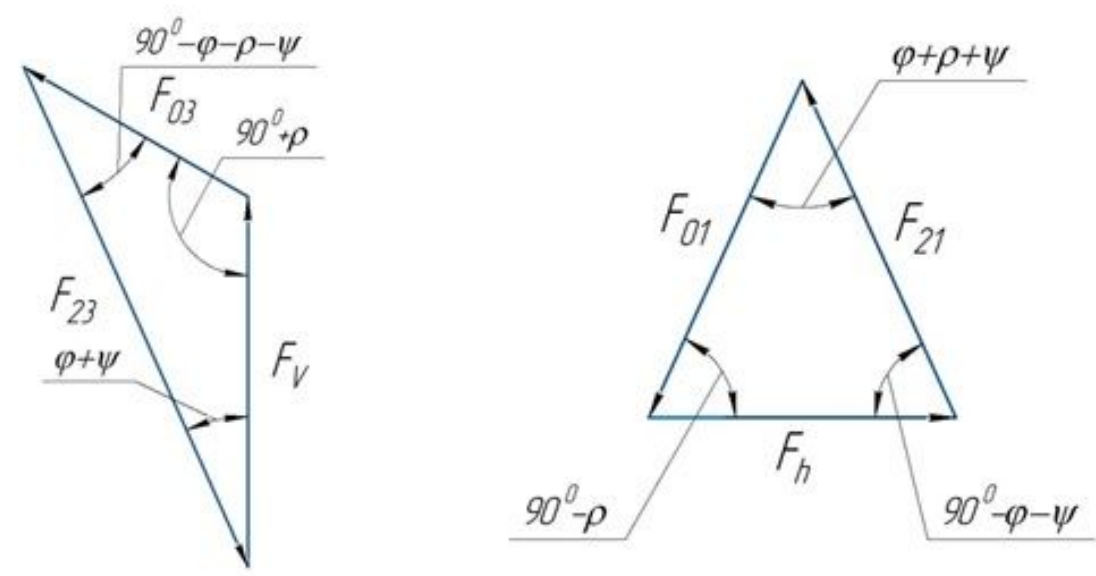

$\mathrm{b}$

Figure 5

Force analysis of a wedge-joint mechanism with a curving wedge: $a$ - design dia-gram; $b$ - forces plans 


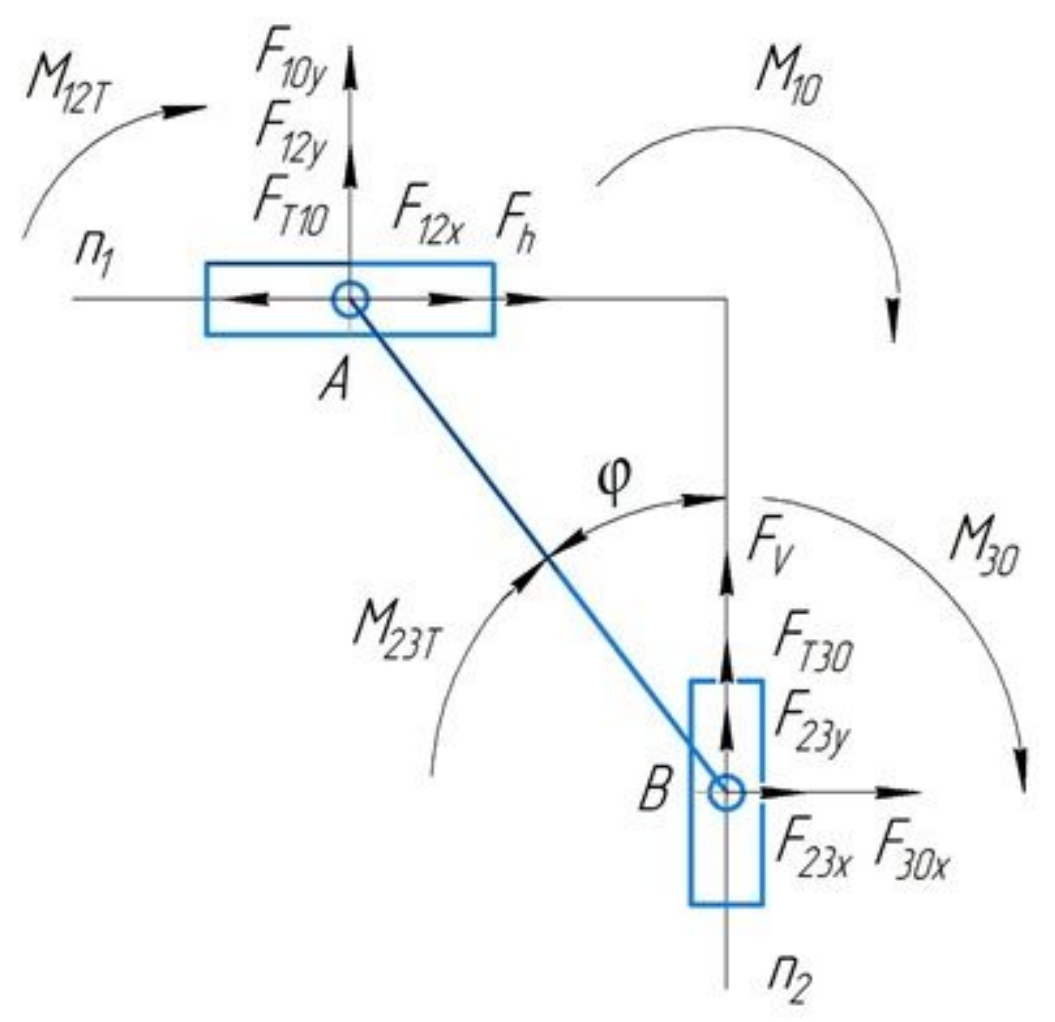

Figure 6

Analytical model of loading a wedge-joint mechanism with a curving wedge $F_{v}, k N$

140

120

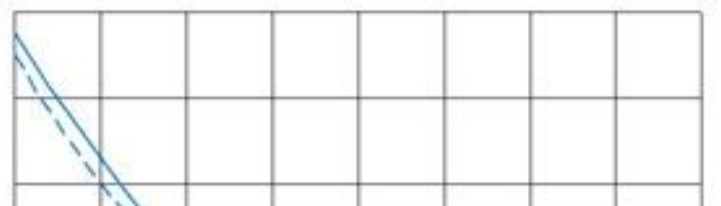

100

80

60

40

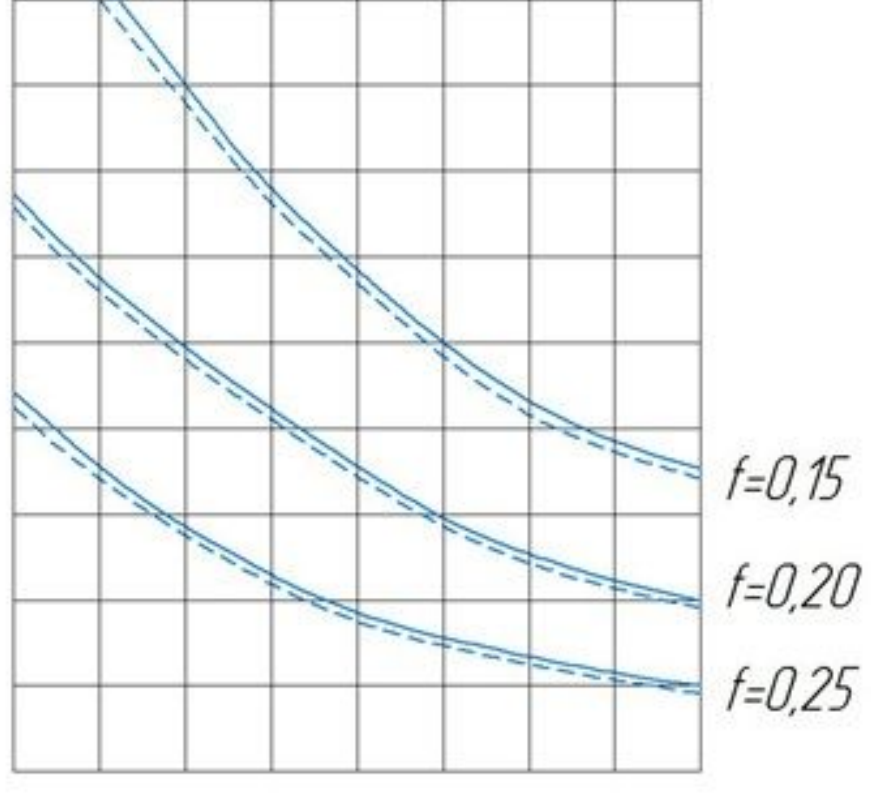

$02468101214 \varphi 9^{\circ}$

Figure 7 
Diagram of the effective resistance force change from the turning angle of the link:

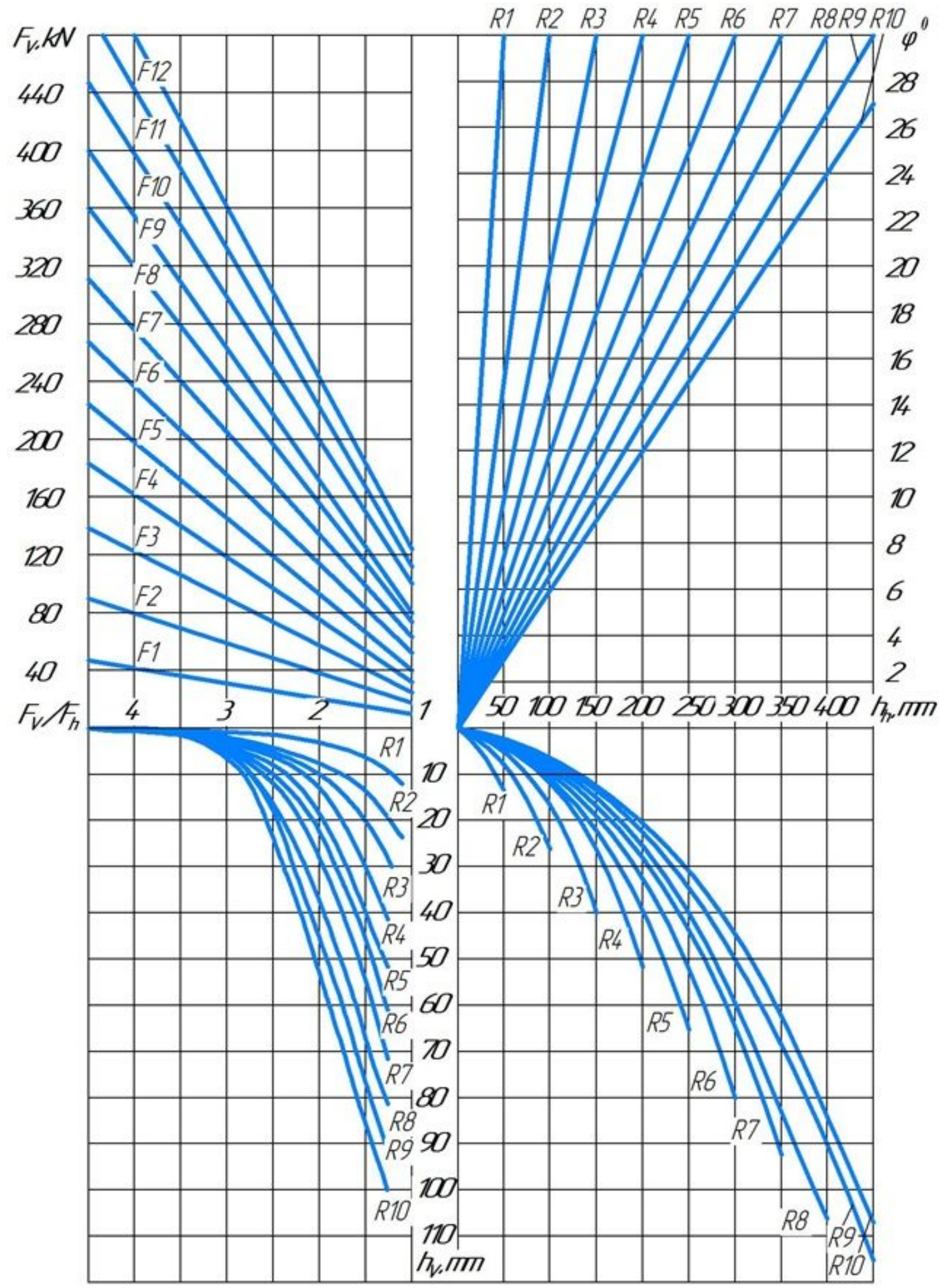

Figure 8

Diagrams for determining the geometric and power parameters of the wedge-joint mechanism with a curving wedge 

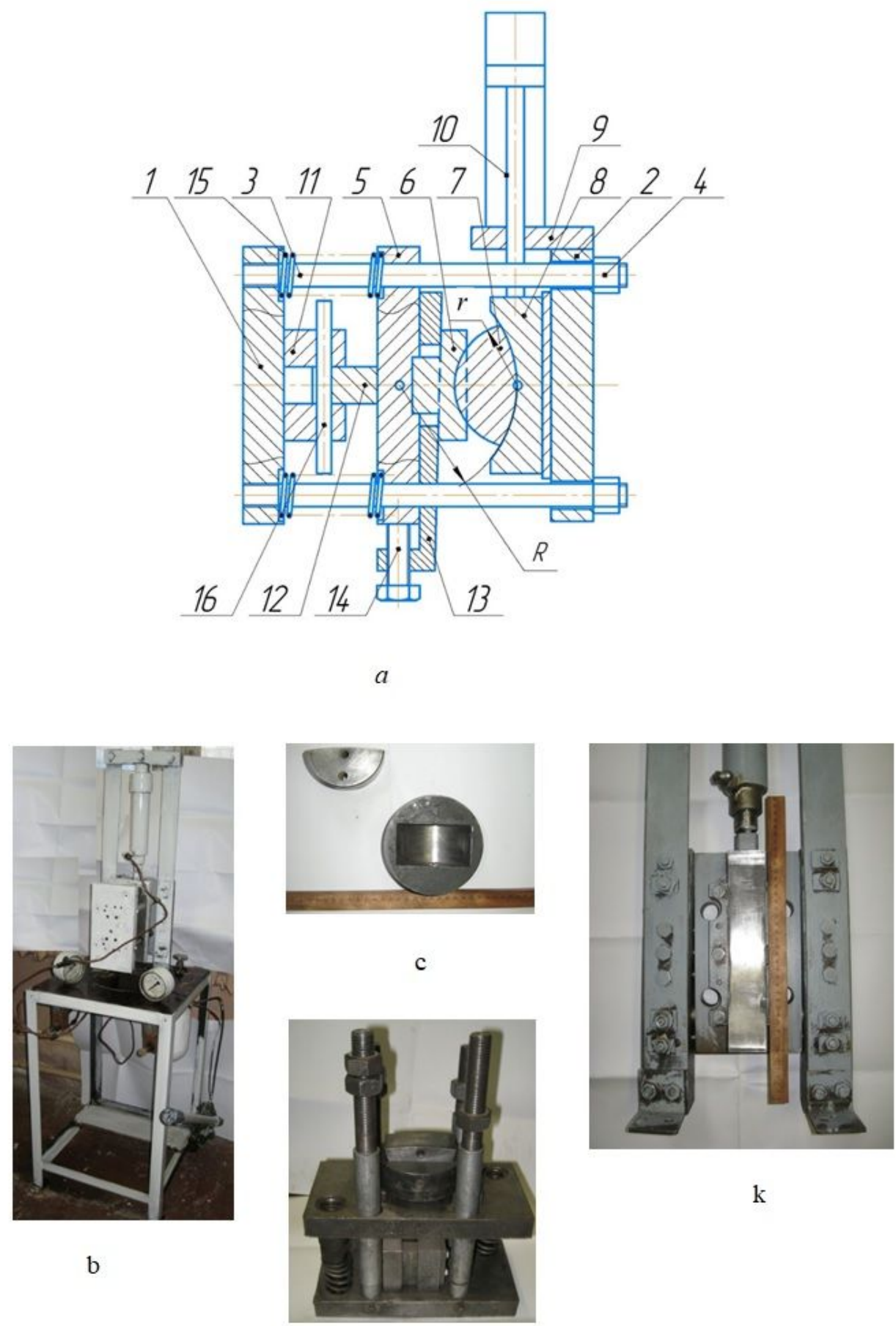

$\mathrm{k}$

$\mathrm{b}$

d

Figure 9

Construction (a) and photographs of the experimental unit: b - complete unit; $\mathrm{c}$ - link and slide; $\mathrm{d}$ - cutting node; $\mathrm{k}$ - drive wedge in guides 


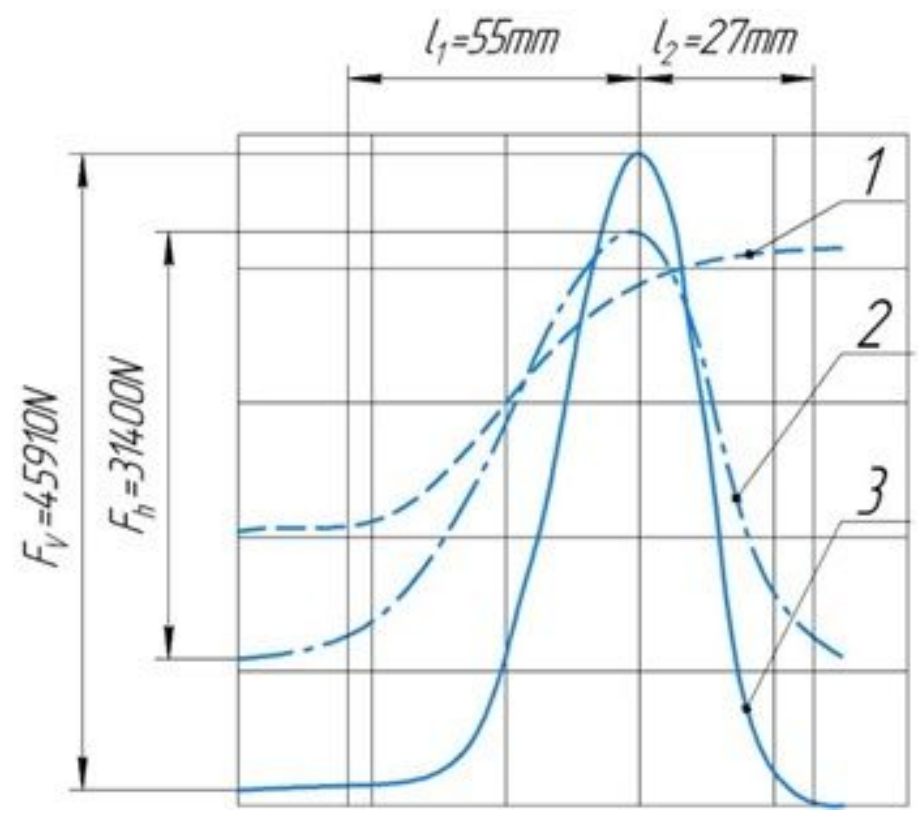

Figure 10

Typical oscillogram

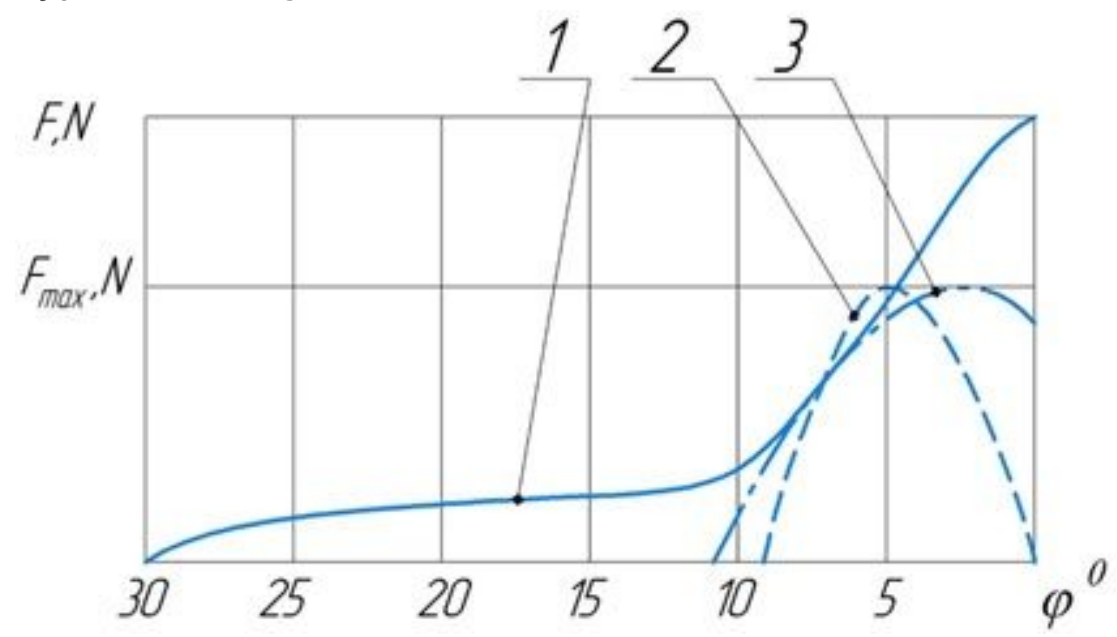

Figure 11

Typical force diagrams of press-forging plants: 1 - toggle press; 2 - wedge-joint press with a curving wedge; 3 - typical force graph at the cutting with a shift 